\title{
100 YEARS LATER Reflecting on Alfred Wegener's Contributions to Tornado Research in Europe
}

\author{
Bogdan Antonescu, Hugo M. A. M. Ricketts, and David M. Schultz
}

\begin{abstract}
Alfred Wegener not only proposed the theory of continental drift but was also a pioneer of modern tornado research in Europe.
\end{abstract}

A lfred Wegener (1880-1930; Fig. 1) is mainly remembered today for his contributions to continental drift from which the modern theory of plate tectonics - "one of the key scientific concepts of the past century" (Greene 2015) - is derived (Romano and Cifelli 2015). Wegener not only made major contributions to geology and geophysics but also to astronomy and geodesy (Wegener 1905; he was an astronomer by training), glaciology (Koch and Wegener 1911; he was a pioneer explorer of Greenland), paleoclimatology (Köppen and Wegener 1924), and meteoritics (Wegener 1925a). He performed research in atmospheric physics and meteorology, including cloud microphysics (e.g., Wegener-Bergeron-Findeisen process; Wegener 1910), thermodynamics (Wegener 1911c), the vertical structure of the chemical composition of the atmosphere (e.g., Wegener 1925b), and atmospheric optics (e.g., a subhelic arc is named the Wegener arc; Wegener 1925c).

Lesser known are his contributions to the study of tornadoes. In 1917, Wegener published the seminal book Wind- und Wasserhosen in Europa (Tornadoes and Waterspouts in Europe). This book not only contains the first pan-European tornado climatology but

- Fig. I. Alfred Wegener (1880-1930), photo taken probably in Marburg around 1910. [Photo courtesy of Bildarchiv Foto Marburg Aufnahme 426.293 via Wikipedia Commons (accessed on 8 Apr 2018).]

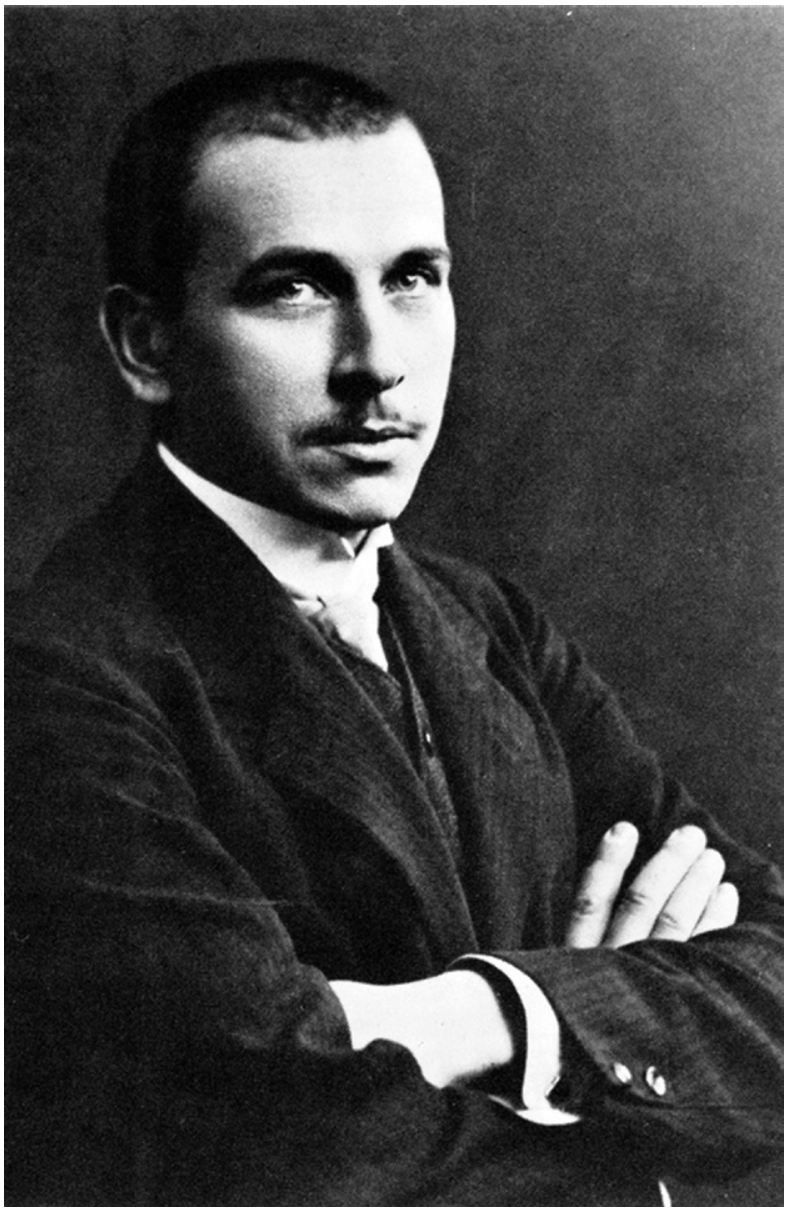


is an exhaustive treatise on all aspects of tornadoes, from the weather associated with tornadoes, tornado rotation, and damage paths to the noise, smell, and electrical phenomena accompanying tornadoes. Wegener wrote the book between January and August 1916 "in the field" during the First World War with limited access to publications and data. But his meticulous working style led to a dataset of 258 tornadoes between 1456 and 1913 and a climatology that is comparable to modern ones.

Wegener's book received relatively little attention at the time of its publication despite being, as a reviewer from the United States wrote in 1920, "a monograph [that] very satisfactorily fills in a missing chapter of modern meteorological science" and that "merits [a] careful study" (Ward 1920, p. 218). One such careful student of the book was the Estonianborn meteorologist Johannes Letzmann (1885-1971), another pioneer researcher on tornadoes in Europe, whose career was inspired by Wegener's book. ${ }^{1}$ Thus, during a period (1883-1937) in which the word "tornado" was banned for weather warnings by the U.S. Weather Bureau and its predecessor the U.S. Army Signal Service (Galway 1985), Wegener and his collaborators were actively researching tornadoes across the Atlantic in Europe (e.g., Wegener 1928; Letzmann 1931; Letzmann and Koschmieder 1937). Unfortunately, because of the relative isolation

\footnotetext{
${ }^{1}$ The interest of the first author of this article on the climatology of tornadoes in Romania, and later on European tornadoes, originated from a sentence in Wind-und Wasserhosen in Europa (Wegener 1917, p. 73) describing a tornado that occurred in Bucharest, Romania, on 9 June 1886 (Hepites 1887).
}

AFFILIATIONS: ANTONESCU, *** RICKETTS,** AND SCHULtZ-School of Earth and Environmental Sciences, University of Manchester, Manchester, United Kingdom

* CURRENT AFFILIATION: ANTONESCU-Remote Sensing Department, National Institute of Research and Development for Optoelectronics INOE 2000, Măgurele, Romania

** ADDITIONAL AFFILIATIONS: ANTONESCU-European Severe Storms Laboratory, Wessling, Germany; RICKETTS-National Centre for Atmospheric Science, University of Manchester, Manchester, United Kingdom CORRESPONDING AUTHOR: Dr. Bogdan Antonescu, bogdan.antonescu@inoe.ro

The abstract for this article can be found in this issue, following the table of contents.

DOI:I0.II75/BAMS-D-17-0316.I

In final form 21 May 2018

(C)2019 American Meteorological Society

For information regarding reuse of this content and general copyright information, consult the AMS Copyright Policy. of German scientists and the declining interest of both researchers and meteorologists in European tornadoes after the Second World War, Wegener's book and articles on tornadoes were almost forgotten. The purpose of this article is to tell the story of Wind- und Wasserhosen in Europa in the context of European research on tornadoes and thus bring greater exposure to the pioneering tornado research of Alfred Wegener. To understand the importance of Wegener's study, we need first to look at the history of tornado research in Europe.

\section{TORNADO RESEARCH IN EUROPE BETWEEN 1840 AND 1910. There is a long} history of tornado observations in Europe and of natural philosophers, starting with Aristotle, who attempted to explain their formation. The systematic study of tornadoes began in the seventeenth century (e.g., Peterson 1982; Antonescu 2017), and the first efforts to develop a pan-European tornado climatology date back to the nineteenth century (Antonescu et al. 2016). In 1840, Jean Charles Athanase Peltier (1785-1845), a French physicist who is credited with the discovery of the thermoelectric effect (i.e., Peltier effect), published a book-length study on tornadoes and waterspouts (Peltier 1840). Peltier became interested in tornadoes when a tornado produced substantial damage in Châtenay-en-France, France, on 18 June 1839 [most likely an enhanced Fujita scale (EF) 4 tornado; Keraunos 2018]. Given his expertise in electricity and meteorology, Peltier was asked by a certain Monsieur Hérelle, whose property was destroyed by the tornado, to determine "the real character of this phenomenon" as his insurance company would only cover damages associated with electrical phenomena (e.g., cloud-to-ground lightning; Peltier 1847). On 28 October 1839, Peltier presented a summary of his findings before the French Academy of Sciences, in which he argued that "everything proves the tornado to be nothing else than a conductor formed of clouds, which serves as a passage for a continual discharge of electricity" (Peltier 1840). His conclusion that tornadoes are an electrical phenomenon supported a popular hypothesis at the end of the eighteenth century and the beginning of the nineteenth century. In his attempt to prove that the electrical hypothesis was the only one able to explain the formation of tornadoes, Peltier (1840) collected 91 reports of tornadoes and waterspouts that occurred in Europe between 1456 and 1839 and thus developed the first pan-European tornado climatology.

The French botanist Charles Martins (1806-99) published the first instructions for conducting 
tornado damage surveys (Martins 1849), which was translated into German a year later (Martins 1850). These instructions-together with an increase in the number of tornado reports during the nineteenth century (from 403 reports between 1800 and 1849 to 900 reports between 1850 and 1899; Antonescu et al. 2016) - showed that European researchers and meteorologists had taken an active interest in collecting tornado reports during this period. Toward the end of the nineteenth century and the beginning of the twentieth century, research focused on tornado damage surveys (e.g., Hepites 1887; Mohorovičić 1892), theoretical aspects (Reye 1872), and laboratory experiments (Weyher 1889). Unfortunately, no other efforts were made to continue pan-European data collection on tornadoes despite the development of national meteorological services and severe weather databases across Europe during this period (Antonescu et al. 2016). Enter the scene, Alfred Wegener.

\section{WEGENER'S RESEARCH ON TORNADOES} BEFORE 1915. In June 1906, a 26-year-old Alfred Wegener embarked on the first of his four Greenland expeditions, the Danish Danmark expedition (190608) led by Ludvig Mylius-Erichsen (1872-1907). The goal of the expedition was to explore and map northeastern Greenland. Alfred Wegener was the physicist and meteorologist of the expedition in charge of the aerological measurements using kites and balloons. On 10 July 1907, Wegener and his fellow explorers ${ }^{2}$ observed a series of waterspouts from Cape Bismarck, in Northeast Greenland National Park, which he described in his expedition diary (Wegener 1907, p. 37):

This morning we saw multiple waterspouts hanging down from a stratocumulus deck. They appeared to be a lot more peaceful than the ones in Europe. I photographed them and prompted Bertelsen to draw them as well as Koch and Lundager to photograph them with their cameras. So, a big waterspout [skypumper in Danish] photography competition "All hands to the pumps!" ‘'Alle Man til Pumperne!" [sic] in Danish\} as Friis said when he saw this. Then I went out with both cameras (with newly loaded plates) and photographed some subjects.

\footnotetext{
${ }^{2}$ Aage Bertelsen (1873-1945) was a Danish painter and one of the Danmark expedition's artists. Johan Peter Koch (1870-1928), a Danish captain and explorer, was the expedition's cartographer. Andreas Lundager (1869-1940) was the expedition's botanist, and Achton Friis (1871-1916), another of the expedition's artists, published a book in 1909 about the expedition (Friis 1913).
}

It is not clear if this was the first time when Wegener witnessed a waterspout, but his diary entry suggests at least an interest in this weather phenomenon (i.e., "lot more peaceful than the ones in Europe"). Unfortunately, our research so far has not uncovered the actual photos or drawings of the waterspouts described by Wegener in his diary. ${ }^{3}$

This experience indicates that, even before the beginning of the First World War, Wegener was already interested in tornadoes and waterspouts. In December 1910, in parallel with putting the finishing touches on his book Thermodynamik der Atmosphäre (Thermodynamics of the Atmosphere; Wegener 1911c), in which he included a short section on tornadoes, Wegener also finished a study on the origin of tornadoes (Wegener 1911d). In this study, Wegener argued that Tromben (singular Trombe), a general term describing all types of whirlwinds (e.g., dust devils, tornadoes, waterspouts) are the descending part of the gust front and are not caused by the heating of the surface layer as was hypothesized by the German mathematician Theodor Reye (1838-1919; Reye 1872). Wegener's argument against Reye's hypothesis was a simple one-"neither cumulus clouds rotate [around a vertical axis] nor does the rising smoke of a cigar," and if cumulus clouds are rotating, their rotation is weak and is not enough to lead to the strong rotation of a tornado (Wegener 1911d, p. 205). Wegener's hypothesis was that tornadoes were associated with the wirbelfaden (vortex filaments) that form along the gust front. The hypothesis was based on observations of a tornado that occurred at Oldenburg, Germany, on 5 July 1890 . The observations were collected and analyzed by the German climatologist Wladimir Köppen (1846-1940), Wegener's mentor and father-in-law, as well as one of the major figures in meteorology at the beginning of the twentieth century. Wegener's hypothesis was also based on photographs published by Frank H. Bigelow (1851-1924), a professor of meteorology in the U.S. Weather Bureau, showing the evolution of a waterspout that occurred off the coast of Cottage City (now Oak Bluffs), Massachusetts, on 19 August 1896 (Bigelow 1906). Using the observations of the Oldenburg tornado, Wegener also speculated that tornadoes formed on the right flank of the precipitation region. This happens, according to Wegener, because the wind turns to the right with increasing height in the Northern Hemisphere, causing

\footnotetext{
${ }^{3}$ A note by Andreas Lundager retrieved from the archives of the Danish Arctic Institute suggests that the two photographic plates mentioned by Wegener "were impossible, it's fair to say overexposed” (Lundager 1907, entry 61).
} 
the volume of precipitation to be rotated to the right with increasing height. Thus, the gust front would grow on the right flank and disappear on the left flank of the storm (Wegener 1911c, p. 209). Wegener concluded that he did not have enough observations to transform his hypothesis into a theory, but "it remains for the future to provide the definitive, strict proof" (Wegener 1911c, p. 209).

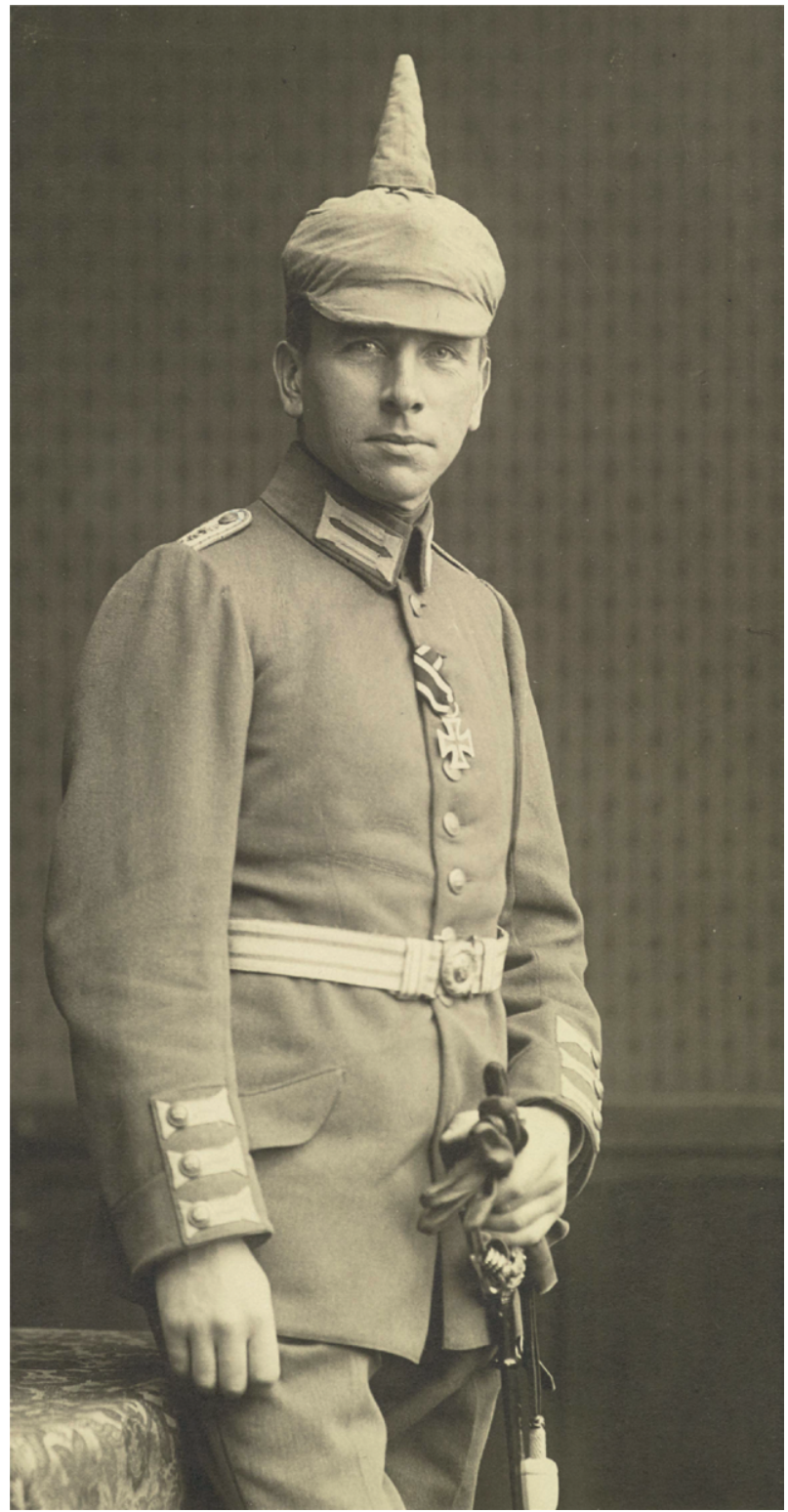

FIG. 2. Alfred Wegener photograph taken in Nov 1914 in Berlin by Bruno Brügner. Wegener is wearing the Iron Cross 2 nd Class awarded for his bravery and wounding during the battle of Namur, Belgium (23 Aug 1914), and the assault of Puisieux, France (4 Oct 1914) (M. Greene 2017, personal communication). Today, the medal is at the Alfred Wegener Institute in Bremerhaven, Germany (courtesy of Deutsches Museum, Munich, Archive, PT_03918_0I_b-0I).
By July 1911, Wegener's interest in tornadoes evolved into a full-fledged research project, being mentioned among other research projects in a letter to Köppen (Wegener 1911b). Over the next year, Wegener's research focused on the stratosphere (Wegener 1911a), continental drift (Wegener 1912a), turbulence (Wegener 1912b), meteoritics (Wegener 1915d), and lunar atmospheric tides (Wegener 1915e). Wegener would return to the study of tornadoes in 1915.

With the outbreak of the First World War, Wegener was mobilized in the German army in August 1914 (Fig. 2) and was injured twice: once in the battle at Namur, Belgium, on 23 August, and again in the assault of Puisieux, France, on 4 October. Wegener was sent home to recover, resulting in some productive months of convalescence. In July 1915, toward the end of his convalescence leave, Wegener received a letter from Köppen with comments emphasizing some inconclusive sections of his book on continental displacement theory. The reply from Wegener contained a self-assessment that allows us to understand his approach to research [Wegener (1915a); translated from German by Greene (2015, p. 343)]:

I think, by the way, that it is a weakness of all my work that I am forever going into too many side issues. I managed to cut out many of them from this book, but I should limit myself to an even greater extent to the straightforward establishment of the displacement.

This tendency for Wegener to diverge from the main topic in his writings sometimes resulted in theoretical digressions and excessive speculation, a trait that had already been identified by both the Austrian meteorologist Felix Exner (1876-1930) in his review of Thermodynamik der Atmosphäre and Köppen in his letter about the manuscript on the displacement theory. This research approach was due to Wegener's belief that new ideas are not so much rooted from theoretical work as from "careful empirical work" (Greene 2015, p. 343). By the end of July 1915, as Wegener was determined to correct these tendencies, he was able to find a project that fit this purpose. He wanted to return to the study of tornadoes, "not necessarily [a subject] á la mode." In this project, he could work only with empirical data and without any speculation (Wegener 1915a). In a letter to Köppen dated 30 July (Wegener 1915b), Wegener provided the first details of this new project for which he "already [had] collected a series of interesting observations and each day I've been collecting new material from 
the literature." From the start, he was planning to write a book on tromben that would include "all the important descriptions word for word and with the original illustrations," short reports about the less important events, and a summary of the existing hypotheses on tornado formation, which would also include his opinions (Wegener 1915a).

Wegener thought that such a book, mainly containing descriptions of tornadoes in Europe without any theoretical speculation, could be read by both professional meteorologists and also by the general public (Wegener 1915c). This approach for studying tornadoes in Europe was used before, for example, by Peltier (1840), who selected reports that supported his hypothesis that tornadoes are electrical phenomena, and by Reye (1872), who included depictions of tornadoes that were "a lot more unnatural than the originals" (Wegener 1915a). Wegener's aim was to develop a catalog that would include original descriptions and depictions of tornadoes and waterspouts, based on which he would construct a climatology and would search for commonalities (e.g., origin, direction of movement, speed, rotation). As indicated by Greene (2015, p. 344), Wegener was familiar with this research approach. For example, Wegener had developed a catalog of historical observations of the motion of the moon going back to the thirteenth century that he used in his dissertation in astronomy (Wegener 1905); he also collected and analyzed historical observations of the color change of meteorites entering the terrestrial atmosphere in a study on the chemical layering of the upper atmosphere (Wegener 1915d).

\section{WRITING WIND- UND WASSERHOSEN IN} EUROPA: 1916. By January 1916, Wegener was the commanding officer of Field Weather Station 12, one of the weather stations of the Field Weather Service of the German army (Greene 2015, p. 346). The station was located on the Western Front at Mülhausen (today in France and known as Mulhouse but in 1916 a part of the German Empire). As a commanding officer with the only responsibility of taking routine weather observations, Wegener devoted his free time to his meteorological research. Thus, the plan to write the book on tornadoes in Europe started to materialize.

In a letter addressed to Köppen from early February 1916, Wegener mentioned that he was continuing his empirical investigations on tornadoes where he was making new discoveries every day and that the source materials were challenging to go through (Wegener 1916d). Gathering source material for a catalog of all past European tornadoes was not easy as Wegener had access only to the collections of the library at the University of Freiburg, Germany. Because of the frequent rail service-Mülhausen was an important administrative center of the German army on the Western Front-Wegener also obtained publications from Köppen from the library of the German Marine Observatory in Hamburg. The meteorologists Julius von Hann (1839-1921) in Vienna and Gustav Hellmann (1854-1939) in Berlin were also able to help Wegener by providing some of the more obscure references on tornadoes (Greene 2015, p. 347).

At the beginning of March, besides working on collecting descriptions of European tornadoes, Wegener started negotiations with his publisher, Vieweg Verlag. The editor wanted to include Wegener's book in a popular science collection. This meant that Wegener's book, with the provisional title Die Großtromben Europas (The Tornadoes of Europe), would not be a thorough scientific study but rather a book for a general audience (Wegener 1916a). Wegener's letters to Köppen from late March showed that Wegener was struggling to organize his material, which by now contained more descriptions than he was planning to include in the manuscript (Wegener 1916b). The variety of descriptions in different languages, and spanning multiple centuries, resulted in difficulties in organizing the material and extracting accurate descriptions.

Despite these problems, and despite his intentions to avoid speculation and theorizing, Wegener started to draw some conclusions concerning the geographical distribution of tornadoes in Europe (Wegener 1916e). First, tornadoes often formed leeward of hills. Second, at the northern foot of the Pyrenees (mainly in the eastern half) and in Sweden, tornadoes seemed to be more frequently observed compared with other regions of Europe. Third, in the United States, "the storms in Spring are rich in tornadoes and the storms on Autumn are poor in tornadoes; [i]n Europe it is the other way around" (Wegener 1916e). Wegener was speculating that this difference in the annual distribution of tornadoes in the United States and Europe "has something to do with the fact that America has the ocean to the east and Europe has it to the west" (Wegener 1916e).

At the end of April, Wegener was back home in Marburg for Easter. He soon learned about an event, which is known today as the Treysa meteor, that occurred on 3 April in Hesse, a state in central Germany. Knowing Wegener's prior interest in meteors (Wegener 1915d), Franz Richarz (1860-1920) and Emanuel Kayser (1845-1927), both professors at the University of Marburg, asked for his help to find the 
location of the meteorite. Based on eyewitness reports, Richarz and Kayser hypothesized that the area where the meteorite fell was close to Marburg. Finding the location of the meteorite not only gave Wegener the opportunity to pursue his interest in this subject but also to understand how eyewitness reports made by citizen scientists could be used for scientific research. This was the essence of his catalog of tornadoes, a collection of observations made mainly by untrained observers that Wegener used to understand the occurrence of this phenomenon in Europe.

Plotting newspaper accounts of the meteorite on a map, Wegener was able to obtain a rough estimate of the landing site. At the beginning of May, he requested an extension of his leave to collect more information about the meteorite. Being approved, he traveled around Treysa and conducted more than 100 interviews during 9-12 May. Putting together all this information, he was able to estimate the landing site $125 \mathrm{~km}$ away from Treysa. According to Greene (2015, p. 350), Wegener's paper on the Treysa meteorite (Wegener 1925a) was "one of the most polished and thorough pieces of work he [Wegener] ever did.” Indeed, the meteorite

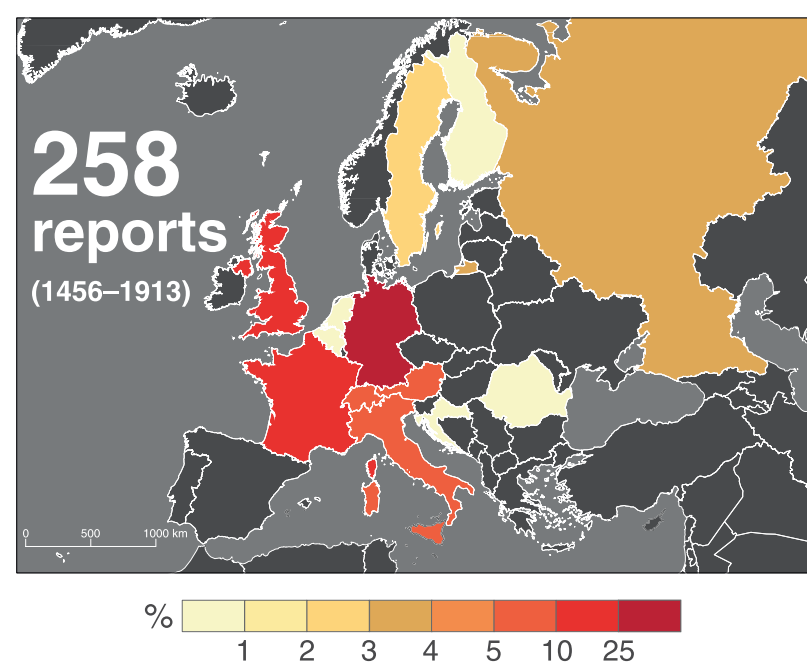

Fig. 3. The spatial distribution of tornado reports in Europe based on the data collected by Wegener (1917) between 1456 and 1913. The percentage of tornado reports for each country (shaded according to the scale) is shown as the percentage from the total number of reports [i.e., 258 reports; adapted from Fig. 3 in Antonescu et al. (2016)]. was later discovered on 5 March 1917, very close to his calculated location.

With these new insights on the utility of reports made by citizen scientists, Wegener returned to Mülhausen in May, making steady progress on the book throughout May and June. In July, the British army started an offensive, and Wegener and his staff were moved to a holding location closer to the front (Greene 2015, p. 354). The Battle of the Somme, fought between July and November 1916, was the largest battle on the Western Front and one of the costliest of World War I. As the British and French offensive was stopped, Wegener returned to Mülhausen ("still situated next to the war, away from the action") and to his working routine. By the second week of July, Wegener was able to send to Köppen the third part of the manuscript. At this point, the only missing chapter from the book was the one containing the hypotheses on the formation of tornadoes (Wegener 1916c). The book was finished "in the field" (as indicated in the preface) in August 1916 and, because of wartime paper shortages in Germany, published one year later.

\section{WIND- UND WASSERHOSEN IN EUROPA:}

1917. Wind- und Wasserhosen in Europa began with a chapter in which Wegener discusses the definition of tornadoes. Wegener considered tornadoes and waterspouts [i.e., Großtromben (tornadoes)] as a distinct phenomenon situated between cyclones and dust devils (Table 1). He then defined tornadoes 
as rotating columns of air stretching from a cumulonimbus cloud to the ground and visible as a cone of condensed water vapor. This chapter on definitions and terminology was followed by a chapter containing detailed descriptions from the literature of 11 tornadoes that occurred between 1535 and 1890 . The next chapter was the core of the book, a catalog containing descriptions and references for 258 tornadoes and waterspouts (Wegener 1917, 58-83). Given that Wegener had limited access to scientific literature because of the war, it is not surprising that the tornado reports were mainly over western Europe (Fig. 3).

Almost 100 years since the publication of Wegener (1917), Antonescu et al. (2016) have revised and updated Wegener's study on tornadoes in Europe. Antonescu et al. (2016, 2017) were able to retrieve information on tornado occurrence for a more geographically diverse area and thus fill the gaps in Wegener (1917). Antonescu et al. (2016) showed that 2,096 tornadoes were reported in 27 countries between 855 and 1919 compared with 258 reports from 14 countries between

1456 and 1913 in the dataset developed by Wegener. Wegener estimated that at least 100 tornadoes occurred each year in Europe. This is an underestimation when compared with results from modern climatologies (i.e., 242 tornadoes per year between 2000 and 2014; Antonescu et al. 2016). Wegener compared his results for the climatology of European tornadoes with a contemporary climatology of U.S. tornadoes developed by John Park Finley (1854-1943; Finley 1887), an American meteorologist and Army Signal
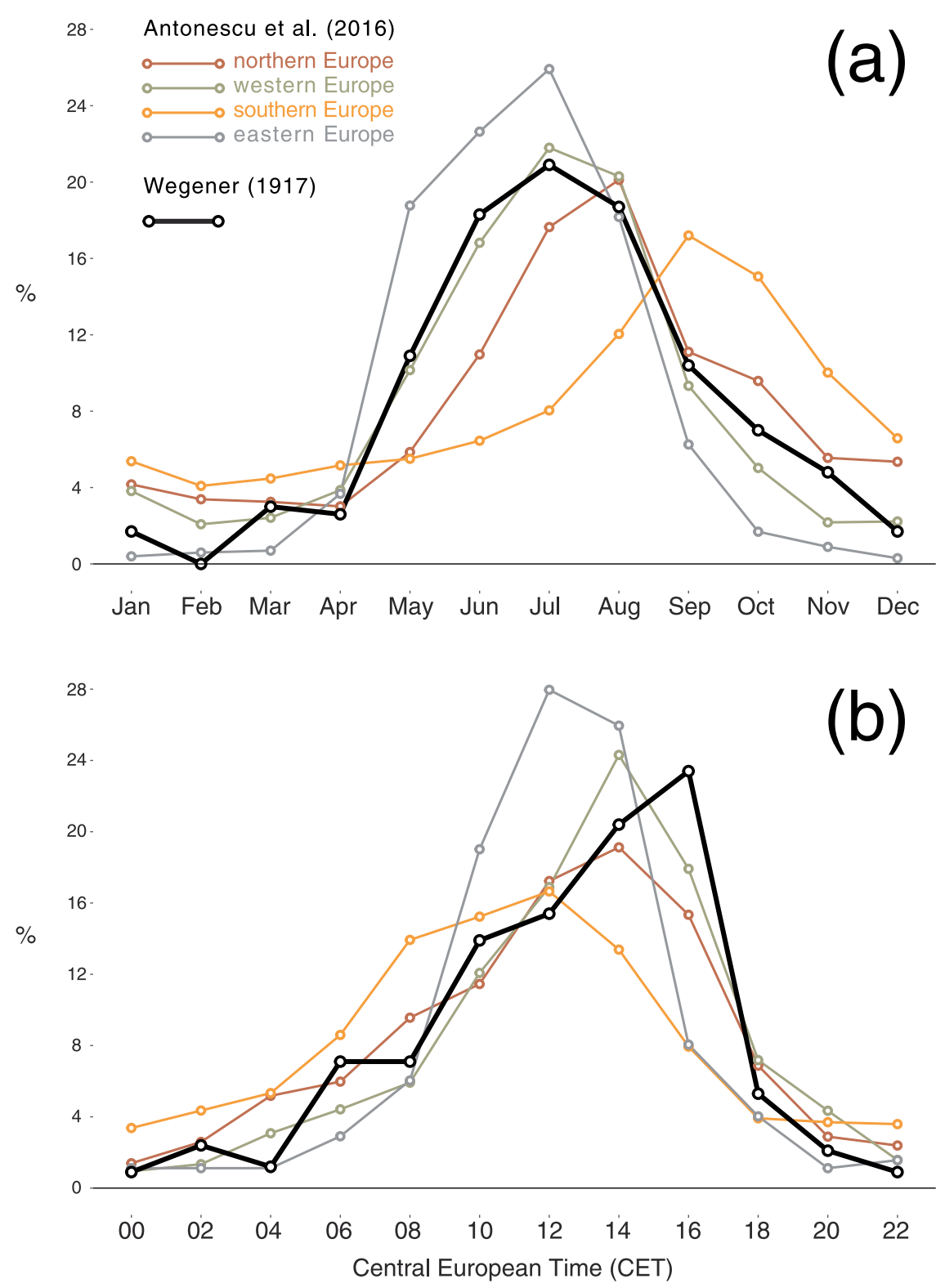

FIG. 4. (a) The monthly and (b) the diurnal occurrence of tornadoes from Antonescu et al. (2016, their Figs. 5 and 7) for northern (red line), western (green line), southern (orange line), and eastern Europe (gray line) and from Wegener (1917; black line). The majority (i.e., 69\%) of tornadoes from Wegener (1917, his Figs. 15 and 16) were reported over western Europe (i.e., France, Belgium, the Netherlands, Germany, Switzerland, and Austria).
Service officer who was the first to study U.S. tornadoes intensively (Galway 1985). Specifically, Wegener showed that, whereas 35 tornadoes were reported in Europe between 1884 and 1887, 777 tornadoes were reported in the United States during a similar interval (1883-86).

Based on his dataset, Wegener showed that the European tornadoes mainly occurred in June-August, with a peak in July (Fig. 4a). That majority (i.e., $69 \%$ ) of the reports from Wegener's dataset are for 
tornadoes that occurred in countries from western Europe (i.e., France, Belgium, the Netherlands, Germany, Switzerland, Austria). Thus, his results are similar with a monthly distribution of tornadoes over western Europe (i.e., June-August, with a peak in July). According to Wegener (1917), tornadoes were reported more frequently between 1400 and 1800 central European time (CET; UTC $+1 \mathrm{~h}$ ), with a peak between 1600 and 1800 UTC compared with other times of the day. For western Europe, Antonescu et al. (2016) identified a maximum between 1200 and 1800 UTC, with a peak between 1400 and 1600 UTC.

The remainder of the book was devoted to the analysis of different aspects of tornadoes, including the weather conditions associated with tornadoes (chapter 5; tornadoes were generally reported east-southeast of the cyclone center), their rotation (chapter 9; of the 25 tornado reports in which the direction of rotation was reported, 18 were cyclonic and 7 anticyclonic), and their associated damages (chapter 14; European tornadoes were less damaging compared with the U.S. tornadoes, and fatalities were reported only in $5 \%$ of all analyzed reports).

The last chapter, "Ansichten über die Entstehung der Tromben" (Views on the Formation of Whirlwinds), discusses a hypothesis on tornado formation. The only hypothesis that Wegener said could explain the formation of tornadoes was the mechanical or the hydrodynamic hypothesis, a hypothesis that can be traced back to Lucretius (99-circa $55 \mathrm{BC}$ ) and further to Aristotle (384-322 BC). As stated by Wegener, "the temperature conditions are not considered the primary cause and the rotation the effect, but the rotation, whether produced mechanically or hydrodynamically, is believed to be the cause of the thermodynamic effects, the latter manifesting themselves in the condensation of the funnel cloud" [Wegener (1917); translated from German by Ward (1920)].

WEGENER'S RESEARCH ON TORNADOES: 1918-1930. Toward the end of the First World War, Wegener was reassigned to the Eastern Front as a commanding officer of the Central Meteorological Station in Sofia, Bulgaria, and then in July 1918 back to the Western Front (Greene 2015, 371-380). In October 1918, Wegener moved to Dorpat (today Tartu) in Estonia where the German army had opened the University of Dorpat, thus allowing some of the German soldiers to continue their studies. Wegener stayed at the University of Dorpat for about a month while the German army evacuated the Baltic countries after the armistice on 11 November 1918. There is one aspect of his stay in Dorpat that had great consequences for his study of tornadoes in Europe-there, Wegener met Johannes Letzmann (1885-1971), an Estonian meteorologist who was interested in storms and who developed a climatology of tornadoes for the Baltic region (Letzmann 1920). Under Wegener's mentorship, Letzmann became even more interested in tornadoes (Peterson 1992a; Lüdecke et al. 2000). Unfortunately, after November 1918, Wegener and Letzmann stopped their collaboration for almost 10 years because Wegener's research interest in tornadoes faded after returning to Marburg (e.g., Wegener published a book on the origin of moon craters; Wegener 1921).

Letzmann remained at the University of Dorpat, studying Wegener's book and continuing his own research on tornadoes. In June 1927, he wrote to Wegener expressing his interest to move to Austria and work with him. Letzmann also mentioned that Wegener's book had inspired him to collect tornado observations for the Baltic area and also to conduct theoretical and experimental work on tornadoes. Letzmann's letter arrived at a very good time. Wegener's interest in tornadoes had just been reawakened by a tornado that occurred on 23 September 1927 near Graz, Austria. Wegener and his wife Else investigated this tornado by walking along the tornado path and talking with the eyewitnesses. Consequently, Wegener agreed to Letzmann's proposal for collaboration, and starting in 1928 , they worked together at the University of Graz where Wegener was a professor.

Their research was focused on finding the mechanism responsible for tornado formation. Wegener was working on a hypothesis that tornadoes were associated with what he called a Mutterwirbel (mother vortex), a vortex tube tilted by the updraft of the thunderstorm. He speculated that this vortex tube would have a cyclonic tornado at one end and an anticyclonic tornado at the other end connected by a horizontal section of the vortex (Wegener 1928; Peterson 1992b). Letzmann and Wegener worked on this hypothesis. They also tried to collect observations, in particular, of the anticyclonic and horizontal part of the vortex tube, that would confirm their hypothesis (Peterson 1992b; Greene 2015). Unfortunately, their collaboration ended because of the tragic death of Wegener in November 1930 during his fourth expedition to Greenland.

During the 1930s, Letzmann became one of the leading figures on tornado research with an interest in the theory of vortex dynamics, analyses of historical tornado events, tornado damage investigations, and laboratory simulations (Dotzek et al. 2005). In 1937, at the invitation of the World Meteorological 
Organization, Letzmann and German meteorologist Harald Koschmieder (1897-1966) published extensive guidelines for the investigation of tornadic phenomena. Unfortunately, these guidelines were initially neglected by the meteorological community, only to be revived four decades later when researchers from the United States started to actively research tornadoes as recommended by Letzmann and Koschmieder (Peterson 1992a).

After the end of the Second World War, Letzmann lost his position at the University of Graz and over the next decades faced a difficult personal situation (Dotzek et al. 2005). By the time of his death in 1971, his research on tornadoes had been forgotten both in Europe and in the United States.

After the 1950s, the lack of researchers or meteorologists working on this topic led to a decline in European tornado research. After 2000, however, interest was revived, mainly because of the efforts of Nikolai Dotzek (1966-2010), who founded the European Severe Storms Laboratory, in part for the purpose of collecting and verifying tornado reports from a pan-European perspective (Feuerstein and Groenemeijer 2011; Groenemeijer et al. 2017).

CONCLUSIONS. Today, Alfred Wegener is largely recognized for being the first to propose a complete theory for continental drift. During his lifetime, however, Wegener was mainly known as a polar explorer and as an atmospheric scientist. We argue that Wegener should also be remembered for his contributions to the study of tornadoes. As recognized by Greene (2015, p. 600), Wegener's book is the only one of his publications that is still cited in the twenty-first century more as a piece of research and less as a piece of history. The isolation of German scientists after the First World War and the decline of the German language as an international language of science (e.g., Gordin 2015) had a great impact on the scientific legacy of Wegener. For example, there are no translations of Wegener (1917), as far as we know.

The story of Wind- und Wasserhosen in Europa is not a surprising one and does not have, to a certain extent, elements of an inspiring story, but "it is Wegener's way [research style] from one end to the other" (M. Greene 2017, personal communication). Wegener thought that his research on tornadoes would be useful for three main reasons (M. Greene 2017, personal communication). First, Wegener had the tendency in his scientific work to go into details about side issues and to include speculations based on empirical observations. He wanted to correct this tendency with his book on tornadoes in Europe by focusing on a single subject without any theoretical speculations. Second, from his investigations into the Treysa meteor, Wegener realized the utility of observations made by citizen scientists, which were the sources of most of the tornado and waterspout reports in his catalog. Third, as a commander of one of the German army field weather stations, Wegener was away from the front, allowing him access to publications from German libraries and free time to work on his research.

Wegener's research on tornadoes in Europe was continued by Johannes Letzmann. After the 1960s, however, both Wegener's and Letzmann's research remained in the background of tornado research in Europe, to be rediscovered after the 1990s, when the interest in European tornadoes increased (e.g., Antonescu et al. 2016). With this article, we hope to celebrate a part of Wegener's lesser-known scientific legacy with the meteorological community, especially outside Europe.

There was a long history of tornado research in Europe before the beginning of the twentieth century when Wegener started to study tornadoes. Wegener (1917) synthesized all the known research that occurred in Europe, as well as a catalog of all known tornadoes and waterspouts in Europe before 1915. Then he meticulously constructed the first pan-European climatology for Europe. One hundred years later, the pan-European tornado climatology was updated following a methodology similar to the one used by Wegener (Antonescu et al. 2016) and shows remarkable confirmation of Wegener's results (e.g., monthly distribution, diurnal distribution).

ACKNOWLEDGMENTS. We are indebted to Mott T. Greene, John B. Magee Professor of Science and Values Emeritus at the University of Puget Sound and affiliate professor of Earth and Space Sciences at the University of Washington, who wrote the definitive biography on Alfred Wegener. That book provided essential details about Wegener's life and research that made this article possible. We also have benefited considerably from discussions with and comments from Prof. Greene. We thank Dr. Bent Nielsen from the Danish Arctic Institute for providing information about the Danish Danmark expedition, in particular about the photographic diary of Andreas Lundager. Antonescu and Ricketts have received funding for this research from the University of Manchester School of Earth and Environmental Sciences Research Fund. Funding for Antonescu and Schultz was provided by the Risk Prediction Initiative of the Bermuda Institute of Ocean Sciences through Grant RPI2.0-2016-SCHULTZ. Partial funding for Antonescu was provided by the AXA Research Fund to 
the University of Manchester for the "Assessing the Threat of Severe Convective Storms across Europe" project and from the Romanian Ministry of Research and Innovation throughout the Core National Programme 33N/16.03.2018. Partial funding for Schultz was provided by the Natural Environment Research Council to the University of Manchester through Grants NE/H008225/1, NE/I005234/1, and NE/N003918/1. We thank the Archiv Deutsches Museum for providing access to Alfred Wegener's correspondence with Wladimir Köppen.

\section{REFERENCES}

Antonescu, B., 2017: Tornadoes and Waterspouts in Europe: Depictions from 1555 to 1910 . Blurb, 100 pp.

—, D. M. Schultz, F. Lomas, and T. Kühne, 2016: Tornadoes in Europe: Synthesis of the observational datasets. Mon. Wea. Rev., 144, 2445-2480, https:// doi.org/10.1175/MWR-D-15-0298.1.

,-- , A. Holzer, and P. Groenemeijer, 2017: Tornadoes in Europe: An underestimated threat. Bull. Amer. Meteor. Soc., 98, 713-728, https://doi.org/10.1175 /BAMS-D-16-0171.1.

Bigelow, F. H., 1906: Studies on the thermodynamics of the atmosphere: VI. The waterspout seen off Cottage City, Mass., in Vineyard Sound, on August 19, 1896. Mon. Wea. Rev., 34, 307-315, https://doi.org/10.1175/1520 -0493(1906)34<307:SOTTOT>2.0.CO;2.

Dotzek, N., A. M. Holzer, R. E. Peterson, and C. Lüdecke, 2005: Alfred Wegener's tornado research and his influence on Johannes Letzmann: Scientific achievements decades ahead of their time. Preprints, Second Alfred Wegener Symp., Bremerhaven, Germany, Alfred Wegener Institute.

Feuerstein, B., and P. Groenemeijer, 2011: In memoriam Nikolai Dotzek. Atmos. Res., 100, 306-309, https:// doi.org/10.1016/j.atmosres.2011.02.005.

Finley, J. P., 1887: Tornadoes: What They Are and How to Observe Them. Insurance Monitor Press, 196 pp.

Friis, A., 1913: Im Grönlandeis mit Mylius-Erichsen Die Danmark-Expedition 1906-1908 (In Greenland with the Mylius-Erichsen Danmark Expedition 1906-1908). Springer, 630 pp.

Galway, J. G., 1985: The first severe storms forecaster. Bull. Amer. Meteor. Soc., 66, 1506-1510, https://doi .org/10.1175/1520-0477(1985)066<1506:JFTFSS >2 $.0 . \mathrm{CO} ; 2$.

Gordin, M. D., 2015: Scientific Babel: The Language of Science from the Fall of Latin to the Rise of English. Profile Books, 415 pp.

Greene, M. T., 2015: Alfred Wegener: Science, Exploration, and the Theory of Continental Drift. Johns Hopkins University Press, 675 pp.
Groenemeijer, P., and Coauthors, 2017: Severe convective storms in Europe: Ten years of research and education at the European Severe Storms Laboratory. Bull. Amer. Meteor. Soc., 98, 2641-2651, https://doi .org/10.1175/BAMS-D-16-0067.1.

Hepites, S. C., 1887: Trombe à Bucharest. Ciel Terre, 7, 234-237.

Keraunos, 2018: Tornade EF4 à Châtenay-en-France (Vald'Oise) le 18 Juin 1839 [An EF4 tornado at Châtenayen-France (Val-d'Oise) on 18 June 1839]. Keraunos, www.keraunos.org/actualites/faits-marquants /1800-1849/tornade-chatenay-en-france-18-juin -1839-trombe-chatenay-ile-de-france.

Koch, J. P., and A. Wegener, 1911: Die glaciologischen Beobachtungen der Danmark-Expedition (The glaciological observations of the Danmark expedition). Medd. Grønland, 46, 1-77.

Köppen, W., and A. Wegener, 1924: Die Klimate der Geologischen Vorzeit (The Climates of the Geological Past). Borntraeger, 255 pp.

Letzmann, J., 1920: Tromben im ostbaltischen Gebiet im ostbaltischen Gebiet (Tornadoes in the east Baltic area). Sitzungsber. Naturforsch. Ges. Univ. Dorpat, 26, 7-46.

_ 1931: Experimentelle Untersuchungen an Luftwirbeln (Experimental investigations on air vortices). Gerlands Beitr. Geophys., 33, 130-172.

- , and H. Koschmieder, 1937: Richtlinien zur Erforschung von Tromben, Tornado, Wasserhosen und Kleintromben (Guidelines for research on funnels, tornadoes, waterspouts and whirlwinds). Int. Meteor. Organ. Klimatologische Komm., 38, 91-110.

Lüdecke, C., E. Tammiksaar, and U. Wutzke, 2000: Alfred Wegener und sein Einfluss auf die Meteorologie an der Universität Dorpat (Tartu) [Alfred Wegener and his influence on meteorology at the University of Dorpat (Tartu)]. Meteor. Z., 9, 175-183, https://doi .org/10.1127/metz/9/2000/175.

Lundager, A., 1907: Fotografi-journal (Photographic diary). Danmark-Ekspeditionen, Arktisk Institute, A $300,139.5$.

Martins, C., 1849: Instructions pour l'observation des trombes terrestres (Instructions for observing tornadoes). Annu. Météor. France, 1, 225-244.

$\_,$1850: Anweisung zur Beobachtung der Windhosen oder Tromben (Instructions for observing waterspouts or tornadoes). Poggendorff's Ann. Phys., 157, 444-467, https://doi.org/10.1002/andp.18501571110.

Mohorovičić, A., 1892: Windhose bei Novska (Slavonien) [Tornado at Novska (Slavonia)]. Meteor. Z., 27,320 .

Peltier, F. A., 1847: Notice sur la Vie et les Travaux Scientifiques de J. C. A. Peltier (Notice on the Life and 
Scientific Work of J. C. A. Peltier). Imprimerie de Édouard Bautruche, 472 pp.

Peltier, J. C. A., 1840: Météorologie: Observations et Recherches Expérimentales sur les Causes qui Concourent à la Formation des Trombes (Meteorology: Observations and Experimental Research on the Causes that Contribute to the Formation of Tornadoes). H. Cousin, $444 \mathrm{pp}$.

Peterson, R. E., 1982: Tornadic activity in Europe-The last half century. Preprints, 12th Int. Conf. on Severe Local Storms, San Antonio, TX, Amer. Meteor. Soc., 63-66.

_ 1992a: Johannes Letzmann: A pioneer in the study of tornadoes. Wea. Forecasting, 7, 166-184, https:// doi.org/10.1175/1520-0434(1992)007<0166:JLAPIT $>2.0 . \mathrm{CO} ; 2$.

_ 1992 b: Letzmann and Koschmieder's “Guidelines for research on funnels, tornadoes, waterspouts and whirlwinds." Bull. Amer. Meteor. Soc., 73, 597-611, https://doi.org/10.1175/1520-0477(1992)073<0597:LA $\mathrm{KFRO}>2.0 . \mathrm{CO} ; 2$.

Reye, T., 1872: Die Wirbelstürme, Tornados und Wettersäulen in der Erdatmosphäre mit Berücksichtigung der Stürme in der Sonnen-Atmosphäre (Hurricanes, Tornadoes and "Weather Columns" in the Earth's Atmosphere with Respect to Storms in the Sun's Atmosphere). Carl Rümpler, $250 \mathrm{pp}$.

Romano, M., and R. L. Cifelli, 2015: 100 years of continental drift. Science, 350, 915-916, https://doi .org/10.1126/science.aad6230.

Ward, R. D., 1920: European tornadoes. Geogr. Rev., 9, 217-218, https://doi.org/10.2307/207266.

Wegener, A., 1905: Die Alfonsinischen Tafeln für den Gebrauch eines modernen Rechners (The Alfonsinian tablets for the use of a modern calculator). Ph.D. thesis, Facultät der Friderich-Wilhelms-Universität zu Berlin, 64 pp., http://digi.evifa.de/viewer/image /BV041981724/3/.

— , 1907: Tagebücher (Diaries) June 1906-August 1908. Deutsches Museum Archive, NL 001/007, www.environmentandsociety.org/exhibitions /wegener-diaries/overview.

__, 1910: Über die Eisphase des Wasserdampfes in der Atmosphäre (On the ice phase of water vapor in the atmosphere). Meteor. Z., 27, 451-459.

__, 1911a: Die Windverhältnisse in der Stratosphäre (The wind conditions in the stratosphere). Meteor. Z., 28, 271-273.

_, $1911 b$ : Letter from Alfred Wegener to Wladimir Köppen from 6/7 July 1911. Deutsches Museum München Handschriftensammlung 596/7 N 1/7, W 024-1911.

_ , 1911c: Thermodynamik der Atmosphäre (Thermodynamics of the Atmosphere). Johann Ambrosius Barth, 331 pp.
— , 1911d: Über den Urspring der Tromben (On the origin of tornadoes). Meteor. Z., 28, 201-209.

_ , 1912a: Die Entstehung der Kontinente (The emergence of continents). Geol. Rundsch., 3, 276-292, https://doi.org/10.1007/BF02202896.

_, 1912 b: Über turbulente Bewegungen in der Atmosphäre (On the turbulent motion in the atmosphere). Meteor. Z., 29, 49-59.

_ 1915 a: Letter from Alfred Wegener to Wladimir Köppen from 13 July 1915. Deutsches Museum München Handschriftensammlung 1968 559/8 N 1/54, W 016-1915.

—, $1915 b$ : Letter from Alfred Wegener to Wladimir Köppen from 30 July 1915. Deutsches Museum München Handschriftensammlung 1968 599/9 N 1/55, W 018-1915.

— $1915 \mathrm{c}$ : Letter from Alfred Wegener to Wladimir Köppen from 7 August 1915. Deutsches Museum München Handschriftensammlung 1968 599/9 N 1/55, W 019-1915.

— , 1915d: Über den Farbenwechsel der Meteore (On the flaring of the meteors). Das Wetter, Sonderheft (Aßmann Festschrift), 62-66.

— 1915e: Zur Frage der atmosphärische Mondgezeiten (On the question of lunar atmospheric tides). Meteor. Z., 32, 253-258.

_ 1916 a: Letter from Alfred Wegener to Wladimir Köppen from 11 March 1916. Deutsches Museum München Handschriftensammlung 1968 600/2 N 1/59, W 002-1916.

— $1916 \mathrm{~b}$ : Letter from Alfred Wegener to Wladimir Köppen from 30 March 1916. Deutsches Museum München Handschriftensammlung 1968 600/3 N 1/60, W 003-1916.

- $1916 \mathrm{c}$ : Letter from Alfred Wegener to Wladimir Köppen from 12 July 1916. Deutsches Museum München Handschriftensammlung 1968 600/8 N 1/65, W 0010-1916.

_, 1916 d: Letter from Alfred Wegener to Wladimir Köppen from 2 February 1916. Deutsches Museum München Handschriftensammlung 1968 600/1 N 1/58, W 001-1916.

_ $1916 \mathrm{e}$ : Letter from Alfred Wegener to Wladimir Köppen from 6 April 1916. Deutsches Museum München Handschriftensammlung 1968 600/4 N 1/61, W 006-1916.

— 1917 : Wind- und Wasserhosen in Europa (Tornadoes and Waterspouts in Europe). Vieweg, 301 pp.

_ , 1921: Die Entstehung der Mondkrater (The Origin of Moon Craters). Friedrich Vieweg and Son, 48 pp. _ , 1925a: Das detonierende Meteor vom 3 April 1916. 3 1/2 Uhr nachmittags in Kurhessen (The detonating meteor from 3 April 1916 at $31 / 2$ in the afternoon 
in Kurhessen). Schr. Ges. Beförderung Gesamten Naturwiss. Marburg, 14, 1-83.

_ 1925 b: Die Temperatur der obersten Atmosphärenschichten (The temperature of the uppermost atmospheric layers). Arch. Dtsch. Seewarte, 42, 402-405.

—, 1925c: Theorie der Haupthalos (Theory of the main halos). Arch. Dtsch. Seewarte, 2, 1-32.
—_, 1928: Beiträge zur Mechanik der Tromben und Tornados (Contributions to the mechanics of vortices and tornadoes). Meteor. Z., 45, 201-214.

Weyher, C. L., 1889: Sur les Tourbillons, Trombes, Tempêtes et Sphères Tournantes: Etude et Expériences (On Whirlwinds, Tornadoes, Thunderstorms and Rotating Spheres: Studies and Experiments). Gauthier-Villars et Fils, 128 pp.

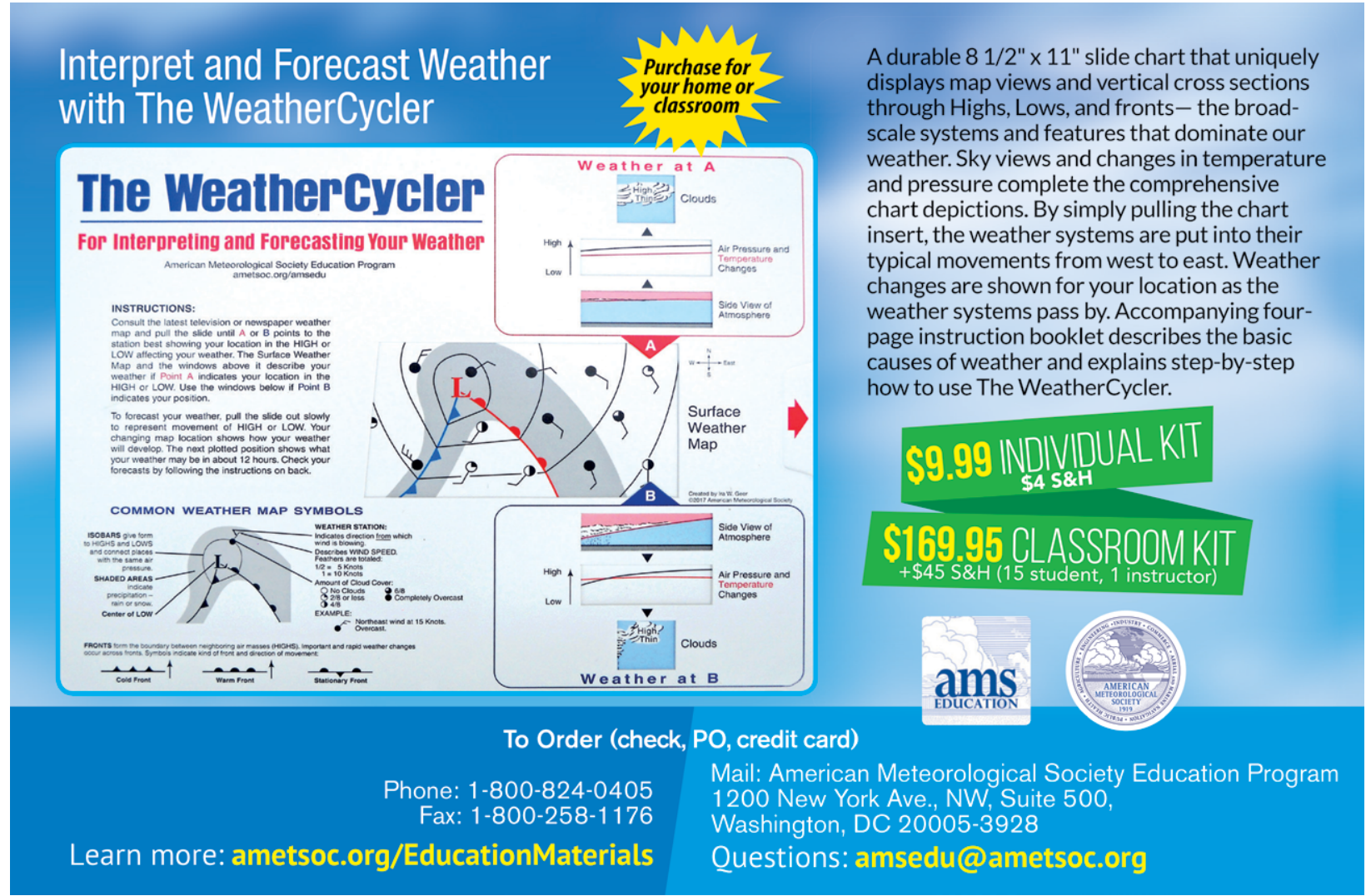

